\title{
Clinical Utility and the Yield of Single Nucleotide Polymorphism Array in Prenatal Diagnosis of Fetal Central Nervous System Abnormalities
}

\author{
Meiying Cai ${ }^{\dagger}$, Hailong Huang ${ }^{\dagger}$, Liangpu $\mathrm{Xu}{ }^{*}$ and $\mathrm{Na} \mathrm{Lin} \mathrm{*}$ \\ Department of the Prenatal Diagnosis Center, Fujian Maternity and Child Health Hospital, Affiliated Hospital of Fujian Medical
} University, Fujian Key Laboratory for Prenatal Diagnosis and Birth Defect, Fuzhou, China

Applying single nucleotide polymorphism (SNP) array to identify the etiology of fetal central nervous system (CNS) abnormality, and exploring its association with chromosomal abnormalities, copy number variations, and obstetrical outcome. 535 fetuses with CNS

\section{OPEN ACCESS}

Edited by:

Hem Chandra Jha,

Indian Institute of Technology Indore,

India

Reviewed by:

Rishein Gupta,

University of Texas at San Antonio,

United States

Alvaro Cerda,

University of La Frontera, Chile

*Correspondence:

Liangpu Xu

xiliangpu@fjmu.edu.cn

$\mathrm{Na}$ Lin

846519465@qq.com

${ }^{+}$These authors have contributed equally to this work

Specialty section:

This article was submitted to

Molecular Diagnostics and Therapeutics, a section of the journal

Frontiers in Molecular Biosciences

Received: 09 February 2021 Accepted: 05 May 2021 Published: 18 May 2021

Citation: Cai M, Huang H, Xu L and Lin N (2021) Clinical Utility and the Yield of Single Nucleotide Polymorphism Array in Prenatal Diagnosis of Fetal Central Nervous System Abnormalities. Front. Mol. Biosci. 8:666115 doi: 10.3389/fmolb.2021.666115 abnormalities were analyzed using karyotype analysis and SNP array. Among the 535 fetuses with CNS abnormalities, chromosomal abnormalities were detected in 36 (6.7\%) of the fetuses, which were consistent with karyotype analysis. Further, additional 41 fetuses with abnormal copy number variations (CNVs) were detected using SNP array (the detection rate of additional abnormal CNVs was $7.7 \%$ ). The rate of chromosomal abnormalities, but not that of pathogenic CNVs in CNS abnormalities with other ultrasound abnormalities was significantly higher than that in isolated CNS abnormalities. The rates of chromosomal abnormalities and pathogenic CNVs in fetuses with spine malformation (50\%), encephalocele (50\%), subependymal cyst (20\%), and microcephaly (16.7\%) were higher than those with other isolated CNS abnormalities. The pregnancies for 36 cases with chromosomal abnormalities, 18 cases with pathogenic CNVs, and three cases with VUS CNVs were terminated. SNP array should be used in the prenatal diagnosis of fetuses with CNS abnormalities, which can enable better prenatal assessment and genetic counseling, and affect obstetrical outcomes.

Keywords: central nervous system, copy number variations, obstetrics, SNP-array, prenatal assessment

\section{INTRODUCTION}

Fetal central nervous system (CNS) abnormality is one of the most common fetal congenital malformations, and its incidence rate is about $1 \%$ (Onkar et al., 2014). The etiology and mechanisms of fetal CNS abnormality are still unknown. A previous study has reported that about $40 \%$ of the pathogenic factors may be environmental and genetic (Huang et al., 2012). CNS abnormalities represent a broad clinical spectrum, including mild ventricular enlargement, posterior fossa widening, hydrocephaly, agenesis of the corpus callosum (ACC), and holoprosencephaly (Hadzagić-Catibusić et al., 2008). With the development of prenatal ultrasound, most fetal CNS abnormalities are found in prenatal ultrasonic examination. Fetuses with abnormal ultrasound are usually recommended to undergo invasive prenatal diagnosis, in order to determine whether they have genetic anomalies, to identify possible etiology, and assess the prognosis of the fetus. 
The traditional karyotype analysis is the gold standard for the diagnosis of chromosomal abnormalities; however, it is difficult to determine the chromosomal microdeletions and microduplications using karyotype analysis, and it takes a long time for cell culture. Chromosome microarray analysis (CMA) is increasingly being used for genetic diagnosis in the medical field, such as for the diagnosis of autism, intellectual disability, developmental delay, miscarriage, or stillbirth, due to the high resolution that it offers (Cukier et al., 2014; Reddy et al., 2012; Sahoo et al., 2017). The American Guidelines for Obstetricians and Gynecologists recommend to replace traditional karyotype analysis with CMA when ultrasound detects one or more large structural abnormalities in the fetus; however this has not been extended to clinical practice (Hanson et al., 2015; Committee Opinion, 2016). CMA can be divided into two types: microarray comparative genomic hybridization and single nucleotide polymorphism (SNP) array, both of which can detect the chromosomal microdeletions and microduplications. SNP array can detect not only copy number variations (CNVs), but also uniparental disomy and chimera.

Through prenatal ultrasound screening, genetic analysis and clinical consultation, the prognosis of fetuses with CNS can be evaluated. Fetuses with severe malformations and chromosomal abnormalities can terminate pregnancy in time, which can effectively control the birth rate of fetuses with severe malformations. It is of great clinical significance for guiding prenatal and postnatal care, reducing birth defects and improving the quality of newborn population. In this study, we used SNP array to explore its clinical value in assessing fetal CNS abnormalities, to better conduct prenatal genetic counseling and evaluate the possible prognosis of fetuses according to the genetic etiology.

\section{MATERIALS AND METHODS}

\section{Clinical Data}

A total of 535 pregnant women with fetal CNS abnormalities were selected from the Prenatal Diagnosis Center of the Fujian Provincial Maternal and Children Health Hospital from November 2016 to July 2020. The study were performed in accordance with the Declaration of Helsinki. All experiments were approved by the local ethics committee at the Fujian Provincial Maternal and Child Health Hospital (2014-042). All parents were wrote informed consent. The gestational age of the pregnant women ranged from 12-38 weeks, with an average of 25.4 weeks. The age of pregnant women ranged from $17-48$ years, with an average age of 28.4 years. Among the 535 cases, there were 318 cases of isolated CNS abnormalities and 217 cases of CNS abnormalities with other ultrasound abnormalities. Isolated CNS abnormalities imply that ultrasound abnormalities are limited to the CNS. CNS abnormalities with other ultrasound abnormalities mean that in addition to CNS abnormalities, abnormalities involving the heart, urinary, digestive, and other systems are also present. The 318 cases of isolated CNS abnormalities included 142 cases of mild ventricular enlargement, 89 cases of choroid plexus cyst, 32 cases of widened posterior fossa, 13 cases of ACC, nine cases of hydrocephaly, nine cases of arachnoid cyst, six cases of microcephaly, five cases of subependymal cyst, four cases of cerebellar hypoplasia, four cases of spine malformation, three cases of Dandy-Walker syndrome, and two cases of encephalocele (Figure 1).

\section{Karyotype Analysis}

According to the routine methods established by our center (Cai et al., 2020), cells from the villi, amniotic fluid, or umbilical cord blood samples of the 535 fetuses with CNS abnormalities were cultured, harvested, prepared, and G-banded. The prepared samples were collected and analyzed using the GSL-120 automatic chromosome scanning platform.

\section{SNP-Array}

Genomic DNA amplification, hybridization, scanning, and data analysis were performed using the Affymetrix's CytoScan $750 \mathrm{~K}$ chip and Illumina kit following the standard operating procedures. Results were interpretated using the following reference databases: DGV (http://projects.tcag.ca/variation), ISCA (https://www. iscaconsortium.org/), OMIM (http://www.omim.org), DECIPHER (htts://decinher.sanger.ac.uk/). According to the corresponding criteria, the results were divided into benign CNVs, CNVs with uncertain clinical significance (VUS), and pathogenic CNVs. In the case of abnormal CNVs, parental samples were also tested to determine the genetic nature of the variation and its clinical significance. Pedigree validation was suggested to all fetuses with pathogenic or probably pathogenic CNVs and VUS CNV to investigate with SNP array to evaluate a possible recurrence risk. The classification of VUS CNV will be reassessed with pedigree validation results.

\section{Statistical Analysis}

SPSS 22.0 software was used for statistical analysis. The rates of chromosomal abnormalities and pathogenicity CNVs were compared between isolated CNS abnormalities groups and CNS abnormalities with other ultrasound abnormalities groups. The $\chi^{2}$ test was used to compare in groups and the difference was considered statistically significant when $p<0.05$.

\section{RESULTS}

\section{Karyotype Analysis of $\mathbf{5 3 5}$ Fetal CNS Abnormalities}

Among the 535 fetuses with CNS abnormalities, 36 fetuses had pathogenic chromosomal abnormalities (6.7\%, 36/535), including trisomy $18(n=11)$, trisomy $21(n=8)$, trisomy 13 $(n=3)$, other chromosome number abnormalities $(\mathrm{n}=2)$, chromosomal structural abnormalities $(n=12 ; 46, \mathrm{XY}, \mathrm{r}$ (p22q36), 46,XY,r (18) (q10), 46,XY,add (21) (q11.2), 46,XX,add (12) (p13.33), 46,XY,del (5) (p14.3), 46,XX,add (5) (p15.3), 46,XX,del (15) (p13), 46,XY,del (4) (q25q28), 46,XY,del (5) (q21q31), del (11) (q14q22), 46,XX,del (13) (q31q34), 46,XY,del (5) (p15p13), 46,X,add (X) (q28)). The fetuses with pathogenic chromosomal abnormalities were resulted in 


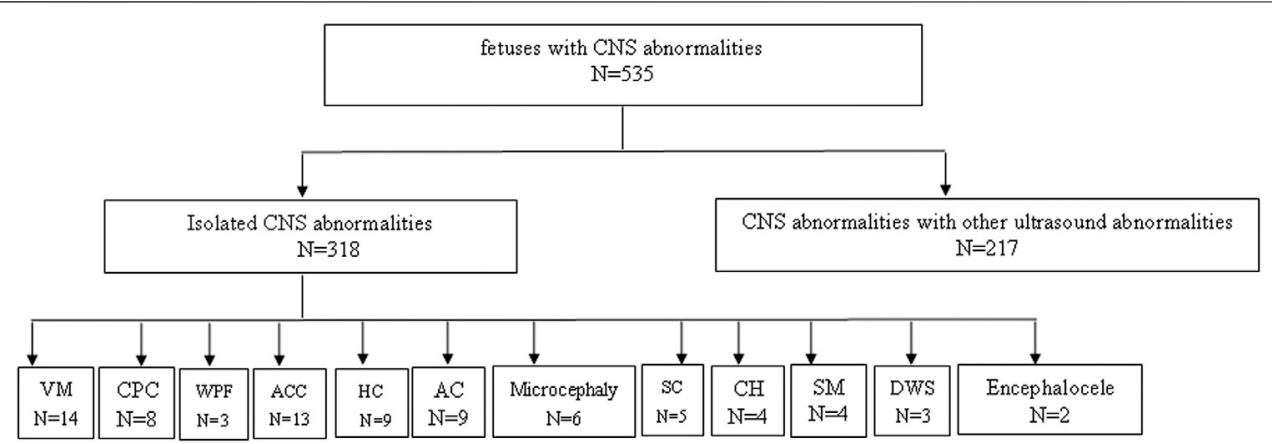

FIGURE 1 | Enrollment of Study Participants, VM, ventricular widening; CPC, choroid plexes cytsts; WPF, widened posterior fossa; ACC, agenesis of the corpus callosum; AC, arachnoid cyst; SC, subependymal cyst; $\mathrm{CH}$, cerebellar hypoplasia; SM, spine malformation; DWS, dandy-walker syndrome; HC, hydrocephaly.

TABLE 1 | Pathogenic chromosomal abnormalities in fetal CNS abnormalities.

\begin{tabular}{|c|c|c|c|}
\hline Case & Karyotype & CNS abnormalities & Extra CNS abnormalities \\
\hline 1 & $47, X X,+18$ & Choroid plexus cyst & - \\
\hline 2 & $47, X Y,+18$ & Choroid plexus cyst & - \\
\hline 3 & $47, X Y,+21$ & Choroid plexus cyst & - \\
\hline 4 & $47, X Y,+21$ & Choroid plexus cyst & - \\
\hline 5 & $47, X X,+13$ & Choroid plexus cyst & - \\
\hline 6 & $47, X X,+21$ & Posterior fossa widened & - \\
\hline 7 & $45, X$ & Posterior fossa widened & - \\
\hline 8 & $47, X X,+21$ & Mild ventriculomegaly & - \\
\hline 9 & 46,XX,add (12) (p13.33) & Mild ventriculomegaly & - \\
\hline 10 & $46, X X$, del (15) (p13) & ACC & - \\
\hline 11 & $47, X X,+21$ & Microcephalus & - \\
\hline 12 & 46,XY,r (p22q36) & Spine malformation & - \\
\hline 13 & $46, X Y, r(18)(q 10)$ & Subependymal cyst & - \\
\hline 14 & $47, X X,+18$ & Posterior fossa widened & Pyelectasis, Single umbilical artery \\
\hline 15 & $47, X Y,+18$ & Choroid plexus cyst & $\mathrm{CHD}$ \\
\hline 16 & $47, X Y,+18$ & Choroid plexus cyst & VSD, Strephenopodia \\
\hline 17 & $47, X Y,+18$ & Choroid plexus cyst & Echogenic bowel \\
\hline 18 & $47, X Y,+18$ & Mild ventriculomegaly & Left ventricular hyperecho \\
\hline 19 & $47, X Y,+18$ & HPE & $\mathrm{CHD}$ \\
\hline 20 & $47, X X,+18$ & Choroid plexus cyst & $\mathrm{CHD}$ \\
\hline 21 & $47, X Y,+18$ & Choroid plexus cyst & $\mathrm{CHD}$ \\
\hline 22 & $47, X X,+18$ & Choroid plexus cyst & $\mathrm{CHD}$ \\
\hline 23 & $47, X Y,+21$ & Mild ventriculomegaly & Thickened nuchal translucency \\
\hline 24 & $47, X X,+21$ & Choroid plexus cyst & Thickened nuchal translucency, Absent nasal bone \\
\hline 25 & $47, X Y,+21$ & Mild ventriculomegaly & Absent nasal bone \\
\hline 26 & $47, X X,+13$ & HPE & Lip and palate clef, CHD \\
\hline 27 & $47, X X,+13$ & HPE & Lip and palate clef, CHD \\
\hline 28 & $45, X[30] / 46, X X[70]$ & Posterior fossa widened & Echogenic bowel \\
\hline 29 & $46, \mathrm{XY}$, add $(21)(\mathrm{q} 11.2)$ & Mild ventriculomegaly & VSD \\
\hline 30 & $46, X Y$, del (5) (p14.3) & Cerebellar hypoplasia & Thickened nuchal translucency, right aortic arch \\
\hline 31 & $46, X X$, add $(5)$ (p15.3) & Spine malformation & Short femur \\
\hline 32 & $46, X Y$, del (4) (q25q28) & Mild ventriculomegaly & VSD \\
\hline 33 & 46,XY,del (5) (q21q31), del (11) (q14q22) & Choroid plexus cyst & Cystic hygroma, Echogenic bowel \\
\hline 34 & $46, X X$, del (13) (q31q34) & HPE & FGR \\
\hline 35 & 46,XY,del (5) (p15p13) & Cerebellar hypoplasia & Thickened nuchal translucency \\
\hline 36 & $46, X, \operatorname{add}(X)(q 28)$ & Choroid plexus cyst & FGR \\
\hline
\end{tabular}

ACC, agenesis of the corpus callosum; CNS, central nervous system; CHD, congenital heart disease; FGR: fetal growth restriction; HPE, holoprosencephaly; P, pathogenicity; VSD: ventricular septal defect.

pregnancy termination (Table 1). The rates of chromosomal abnormalities were $4.1 \%(13 / 318)$ in isolated CNS abnormalities, and $10.6 \%(23 / 217)$ in CNS abnormalities with other ultrasound abnormalities. The rate of chromosomal abnormalities in CNS abnormalities with other ultrasound abnormalities was significantly higher than that in isolated 
TABLE 2 | The rates of chromosomal abnormalities in isolated CNS abnormalities and CNS abnormalities with other ultrasound abnormalities.

\begin{tabular}{|c|c|c|c|c|c|c|c|c|}
\hline Classification & $\begin{array}{c}\text { Number of } \\
\text { fetuses }\end{array}$ & $\begin{array}{l}\text { Number of } \\
\text { chromosomal } \\
\text { abnormalities }\end{array}$ & $\begin{array}{c}\text { Trisomy } \\
18\end{array}$ & $\begin{array}{c}\text { Trisomy } \\
21\end{array}$ & $\begin{array}{c}\text { Trisomy } \\
13\end{array}$ & $\begin{array}{c}\text { Other chromosome } \\
\text { number } \\
\text { abnormalities }\end{array}$ & $\begin{array}{l}\text { Structural } \\
\text { chromosomal } \\
\text { abnormalities }\end{array}$ & p-values \\
\hline $\begin{array}{l}\text { Isolated CNS } \\
\text { abnormalities }\end{array}$ & 318 & $13(4.1 \%)$ & 2 & 5 & 1 & 1 & 4 & - \\
\hline $\begin{array}{l}\text { CNS abnormalities with } \\
\text { other ultrasound } \\
\text { abnormalities }\end{array}$ & 217 & 23 (10.6\%) & 9 & 3 & 2 & 1 & 8 & - \\
\hline Total & 535 & 36 (6.7\%) & 11 & 8 & 3 & 2 & 12 & 0.003 \\
\hline
\end{tabular}

CNS anomalies, and the difference was statistically significant $(P=0.003, p<0.05)($ Table 2).

\section{Single Nucleotide Polymorphism Array of 535 Fetal CNS Abnormalities}

Among the 535 fetuses with CNS abnormalities, in addition to 36 fetuses of chromosomal abnormalities that were detected using karyotype analysis, additional 41 fetuses of abnormal CNVs were detected by SNP array. The detection rate of additional abnormal CNVs was $7.7 \%$ (41/535). Among 41 fetuses with abnormal CNVs, 18 were pathogenic CNVs, and 23 were VUS CNVs. In the 318 cases of isolated CNS abnormalities group, there were a total of 26 cases with abnormal CNVs, including eight cases with pathogenic CNVs and 18 cases with VUS CNVs. In the 217 cases of CNS abnormalities with other ultrasound abnormalities group, there were a total of 15 cases with abnormal CNVs, including 10 cases with pathogenic CNVs and five cases with VUS CNVs. The size of the CNVs detected was between 0.2 and $7.7 \mathrm{Mb}$. Among the 18 cases of pathogenic CNVs, eight cases had known microdeletion/microduplication syndrome, five cases had 16p11.2 microdeletion syndrome, two cases had 22q11.2 microdeletion syndrome, and one case had Miller-Dieker syndrome (17p13.3p13.2 microdeletion syndrome) (Table 3). Among 23 fetuses with VUS CNVs, 15 cases had microduplication, seven cases had microdeletion, and one case had loss of heterozygosity (Table 4).

The rates of pathogenic CNVs were 2.5\% (8/318) and 4.6\% (10/217) in isolated CNS abnormalities and CNS abnormalities with other ultrasound abnormalities, respectively. The rate of pathogenic CNVs in CNS abnormalities with other ultrasound anomalies was higher than that in isolated CNS abnormalities, but the difference was not statistically significant $(P=0.187, p>$ 0.05) (Table 5).

\section{The Detection Rate of Chromosomal Abnormalities and Pathogenic CNVs in Fetuses With Isolated CNS Abnormalities}

The rate of chromosomal abnormalities and pathogenic CNVs in fetuses with isolated CNS abnormalities was $6.6 \%$. The rates of chromosomal abnormalities and pathogenic CNVs in fetuses with spine malformation (50\%), encephalocele (50\%), subependymal cyst (20\%), and microcephaly (16.7\%) were higher than those with other isolated CNS abnormalities. The largest number of fetuses with isolated CNS abnormalities were 142 fetuses with mild ventricular enlargement, accounting for $44.7 \%(142 / 535)$ of the total, but the detection rate of chromosomal abnormalities and pathogenic CNVs was $2.8 \%$ (4/142) (Table 6).

\section{Obstetrical Outcomes}

Among the 535 fetal CNS abnormalities, 523 were successfully followed up. The pregnancies were terminated for fetuses with chromosomal abnormalities $(n=36)$, pathogenic CNVs $(n=18)$, and VUS CNVs $(n=3)$. In addition, pregnancies were terminated for 25 fetuses with CNS abnormalities. Although karyotype analysis and SNP array showed normal results, 13 fetuses with severe nervous system malformations and 12 fetuses with severe multiple malformations accounted for the termination of respective pregnancies.

\section{DISCUSSION}

The main factor leading to the malformation of the central nervous system may be genetic. The malformation of the central nervous system may cause the brain ridge liquid circulation disorder, and left ventricle deformation or expansion. Central nervous system once appear abnormal, is likely to lead to fetal abnormal changes of several brain ventricles. Fetuses with CNS abnormalities have a poor prognosis with serious consequences, and due to their disabling nature, they pose a great burden to individuals, families, and society after birth. Therefore, it is necessary to take intervention measures such as intrauterine treatment and termination of pregnancy as early as possible.

In this study, SNP array and traditional karyotype analysis were performed on fetuses with CNS abnormalities with or without other ultrasound abnormalities. Traditional karyotype analysis detected 36 abnormal karyotypes, and the detection rate of chromosomal abnormalities was $6.7 \%$. In addition to the 36 cases of CNVs consistent with karyotype analysis, SNP array detected 41 abnormal CNVs (an additional detection rate of 7.7\%). These 41 abnormal CNVs were different in sizes and could not be identified by traditional karyotype analysis. The results of 
TABLE 3 | The pathogenic CNVs in fetal CNS abnormalities.

\begin{tabular}{|c|c|c|c|c|c|}
\hline Case & Microarray nomenclature & $\begin{array}{l}\text { Size } \\
(\mathrm{Mb})\end{array}$ & CNS abnormalities & $\begin{array}{c}\text { Extra CNS } \\
\text { abnormalities }\end{array}$ & Inheritance \\
\hline 1 & arr [hg19]16p11.2 $(29,567,296-30,190,029) \times 1$ & 0.6 & Mild ventriculomegaly & - & de novo \\
\hline \multirow[t]{3}{*}{2} & arr [hg19]Xq28 $(152,446,333-153,581,657) \times 3,1$ 336.33p36.23 $(849,466-592,172) \times 1,1 q 44(246,015,892-249,224,684) \times 3$ & 1.1 & Mild ventriculomegaly & - & de novo \\
\hline & & 7.7 & & & \\
\hline & & 3.2 & & & \\
\hline 3 & arr [hg19] $7 q 36.3(155,347,675-156,348,660) \times 3$ & 1.0 & Hydrocephaly & - & de novo \\
\hline 4 & arr [hg19]16p11.2 $(29,591,326-30,176,508) \times 1$ & 0.6 & Hydrocephaly & - & de novo \\
\hline 5 & arr [hg19]16p11.2 $(29,580,020-30,190,029) \times 1$ & 0.6 & Spine malformation & - & de novo \\
\hline 6 & arr [hg19]16p11.2 $(28,819,028-29,051,191) \times 1$ & 0.2 & Encephalocele & - & de novo \\
\hline 7 & arr [hg19]17p12 $(14,099,504-15,491,533) \times 1$ & 1.3 & Posterior fossa widened & - & de novo \\
\hline 8 & arr [hg19]22q11.2 $(18,648,855-21,800,471) \times 1$ & 3.1 & Choroid plexus cyst & - & de novo \\
\hline 9 & arr [hg19]5q35.2q35.3 $(175,416,095-177,482,506) \times 1$ & 2.0 & Mild ventriculomegaly & Polyhydramnios & de novo \\
\hline 10 & arr [hg19]15q11.2 $(22,770,421-23,277,436) \times 1$ & 0.5 & $\begin{array}{l}\text { Dandy-Walker } \\
\text { syndrome }\end{array}$ & VSD & Paternal \\
\hline 11 & arr [hg19]16p13.3 $(85,880-536,631) \times 1,17 q 24.2 q 25.3(64,966,574-81,041,823) \times 3$ & 0.4 & Mild ventriculomegaly & $\begin{array}{l}\text { FGR, VSD, Persistent left } \\
\text { superior vena cava }\end{array}$ & de novo \\
\hline 12 & arr [hg19]17p13.3p13.2 $(525-5,204,373) \times 1$ & 5.2 & $\begin{array}{l}\text { Mild ventriculomegaly, } \\
\text { Cerebellar hypoplasia }\end{array}$ & Strephenopodia & de novo \\
\hline 13 & arr [hg19]16p13.11 $(15,422,960-16,508,123) \times 1$ & 1.0 & Mild ventriculomegaly & Left ventricular hyperecho & de novo \\
\hline 14 & arr [hg19]22q11.2 $(20,730,143-21,800,471) \times 1$ & 1.0 & Choroid plexus cyst & $\begin{array}{l}\text { Strephenopodia, } \\
\text { Polyhydramnios }\end{array}$ & de novo \\
\hline 15 & arr [hg19]16p11.2 $(28,810,324-29,032,280) \times 1$ & 0.2 & Mild ventriculomegaly & $\begin{array}{l}\text { Echogenic bowel, Left } \\
\text { ventricular hyperecho }\end{array}$ & de novo \\
\hline 16 & $\operatorname{arr}[\mathrm{hg} 19] 15 q 13.2 q 13.3(31,104,220-32,444,043) \times 1$ & 1.3 & $\begin{array}{l}\text { Holoprosencephaly } \\
\text { (HPE) }\end{array}$ & $\begin{array}{l}\mathrm{CHD} \text {, Single umbilical } \\
\text { artery }\end{array}$ & de novo \\
\hline 17 & $\operatorname{arr}[\mathrm{hg} 19] 2 \mathrm{2q} 13(111,397,196-113,111,856) \times 1$ & 1.7 & Subependymal cyst & $\begin{array}{l}\text { VSD, Persistent left } \\
\text { superior vena cava, } \\
\text { Thickened nuchal } \\
\text { translucency }\end{array}$ & Maternal \\
\hline 18 & arr [hg19]1p36.33p36.32 $(849,466-4,894,800) \times 1$ & 4.0 & Mild ventriculomegaly & Renal cysts & de novo \\
\hline
\end{tabular}

CNS, Central Nervous System; ACC, Agenesis of the corpus callosum; CNVs, copy number variations; CHD, congenital heart disease; FGR: fetal growth restriction; TP, termination of pregnancy; VSD: ventricular septal defect. 
TABLE 4 | The VUS CNVs in fetal CNS abnormalities.

\begin{tabular}{|c|c|c|c|c|c|c|}
\hline Case & Microarray nomenclature & Size (Mb) & CNS abnormalities & Extra CNS abnormalities & Obstetrical outcomes & Inheritance \\
\hline 1 & $\begin{array}{l}\operatorname{arr}[\text { hg19]1q21.1 } \\
(145,375,770-145,770,627) \times 1\end{array}$ & 0.7 & Mild ventriculomegaly & - & TD & - \\
\hline 2 & $\begin{array}{l}\operatorname{arr}[\mathrm{hg} 19] 16 \mathrm{p} 13.11 \\
(15,058,820-16,309,046) \times 3\end{array}$ & 1.3 & Mild ventriculomegaly & - & TD & Paternal \\
\hline 3 & $\begin{array}{l}\operatorname{arr}[\text { hg19]3p22.1 } \\
(42,875,130-43,309,436) \times 1\end{array}$ & 0.4 & Mild ventriculomegaly & - & TD & - \\
\hline 4 & $\begin{array}{l}\operatorname{arr}[\text { hg19]3p25.2 } \\
(12,183,082-12,669,247) \times 3\end{array}$ & 0.5 & Mild ventriculomegaly & - & TD & - \\
\hline 5 & $\begin{array}{l}\text { arr[hg19]3p26.3 } \\
(1,855,754-2,663,625) \times 1\end{array}$ & 0.8 & Mild ventriculomegaly & - & TD & - \\
\hline 6 & $\begin{array}{l}\operatorname{arr}[\mathrm{hg} 19] 16 q 23.1 \\
(75,275,963-76-432-398) \times 3\end{array}$ & 1.2 & Mild ventriculomegaly & - & TD & - \\
\hline 7 & $\begin{array}{l}\text { arr[hg19]3q26.1q29 } \\
(163,256,369-197,791,601) \\
\text { hmz,5p13.1p11 } \\
(41,029,137-46,313,469) \\
\text { hmz,6q24.2q25 } \\
(143,341,406-161,527,784) \\
\text { hmz,12q13.2q21.2 } \\
(56,011,100-77,134,151) \\
\text { hmz,17q21.2q21.32 } \\
(39,639,602-45,479,706) \\
h m z, 21 \mathrm{q} 21.3 \mathrm{q} 22.2 \\
(28,124,165-42,352,287) \mathrm{hmz}\end{array}$ & 99.1 & Mild ventriculomegaly & - & TD & - \\
\hline 8 & $\begin{array}{l}\operatorname{arr}[\mathrm{hg} 19] 14 \mathrm{q} 21.2 \mathrm{q} 21.3 \\
(46,782,405-49,288,860) \times 1\end{array}$ & 2.5 & Hydrocephaly & - & TP & - \\
\hline 9 & $\begin{array}{l}\operatorname{arr}[\mathrm{hg} 19] 15 q 13.3 \\
(31,999,631-32,444,043) \times 3\end{array}$ & 0.4 & Hydrocephaly & - & TP & - \\
\hline 10 & $\begin{array}{l}\operatorname{arr}[\mathrm{hg} 19] 2 \mathrm{2q} 36.1 \mathrm{q} 36.2 \\
(224,459,152-225,330,583) \times 3\end{array}$ & 0.9 & Posterior fossa widened & - & TD & - \\
\hline 11 & $\begin{array}{l}\text { arr[hg19]10q24.31q24.32 } \\
(102,972,457-103,179,063) \times 3\end{array}$ & 0.2 & Posterior fossa widened & - & TD & - \\
\hline 12 & $\begin{array}{l}\operatorname{arr}[\text { hg19]18q21.33 } \\
(59,581,098-59,784,858) \times 1\end{array}$ & 0.2 & ACC & - & TD & - \\
\hline 13 & $\begin{array}{l}\operatorname{arr}[\text { hg19] } 5 q 35.3 \\
(179,194,643-179,767,135) \times 3\end{array}$ & 0.6 & ACC & - & TD & Maternal \\
\hline 14 & $\begin{array}{l}\operatorname{arr}[\mathrm{hg} 19] 20 \mathrm{q} 13.2 \\
(53,545,723-54,866,110) \times 3\end{array}$ & 1.3 & Choroid plexus cyst & - & TD & - \\
\hline 15 & $\begin{array}{l}\text { arr[hg19]15q13.3 } \\
(32,011,458-32,444,043) \times 3\end{array}$ & 0.4 & Choroid plexus cyst & - & TD & - \\
\hline 16 & $\begin{array}{l}\operatorname{arr}[\mathrm{hg} 19] 8 \mathrm{p} 23.2 \\
(3,703,883-5,940,433) \times 3\end{array}$ & 2.2 & Choroid plexus cyst & - & TD & - \\
\hline 17 & $\begin{array}{l}\text { arr[hg19] 1q31.1 } \\
(186,148,297-190,257,668) \times 3\end{array}$ & 4.1 & Choroid plexus cyst & - & TD & Paternal \\
\hline 18 & $\begin{array}{l}\operatorname{arr}[\text { hg19] } 15 q 11.2 \\
(22,770,421-23,625,785) \times 1\end{array}$ & 0.8 & Choroid plexus cyst & - & TD & Paternal \\
\hline 19 & $\begin{array}{l}\operatorname{arr}[\mathrm{hg} 19] 1 \mathrm{q} 21.1 \mathrm{q} 21.2 \\
(145,958,361-147,830,830) \times 3\end{array}$ & 1.8 & Subependymal cyst & $\mathrm{CHD}$ & TD & - \\
\hline 20 & $\begin{array}{l}\operatorname{arr}[\text { hg19]11p15.1p14.3 } \\
(20,745,930-21,780,075) \times 3\end{array}$ & 1.0 & Mild ventriculomegaly & VSD, Hydronephrosis & TD & - \\
\hline 21 & $\begin{array}{l}\operatorname{arr}[\text { hg19]18q11.2 } \\
(19,620,590-21,572,153) \times 3\end{array}$ & 1.9 & Mild ventriculomegaly & Tricuspid regurgitation & TD & Paternal \\
\hline 22 & $\begin{array}{l}\operatorname{arr}[\mathrm{hg} 19] 15 \mathrm{q} 13.3 \\
(32,021,609-32,444,043) \times 3\end{array}$ & 0.4 & Mild ventriculomegaly & Echogenic bowel, Left ventricular hyperecho & TD & - \\
\hline 23 & $\begin{array}{l}\operatorname{arr}[\mathrm{hg} 19] 1 \mathrm{p} 31.3(61,886 \\
890-63,701,576) \times 1\end{array}$ & 1.8 & Spine malformation & Thickened nuchal translucency & TP & de novo \\
\hline
\end{tabular}

CNS, Central Nervous System; ACC, Agenesis of the corpus callosum; CNVs, copy number variations; CHD, congenital heart disease; TD, term delivery; TP, termination of pregnancy; VSD: ventricular septal defect; VUS, uncertain clinical significance.

this study indicated that the etiologies of fetal CNS abnormalities were related to chromosomal microdeletions and/or microduplications, in addition to chromosomal abnormalities. The use of SNP array can make up for the shortcomings of the traditional karyotype analysis. For fetal CNS abnormalities with normal karyotype analysis, SNP array should be suggested for further detection.

Among the chromosomal abnormalities in fetuses with CNS abnormalities, trisomy 18 and chromosomal structural abnormalities were the most common, accounting for $31.4 \%$ $(11 / 36)$ and $34.3 \%(12 / 36)$, respectively, followed by trisomy 21 , trisomy 13 , and other chromosomal number abnormalities. The detection rate of chromosomal abnormalities in CNS abnormalities with other ultrasound abnormalities was significantly higher than that in isolated CNS abnormalities (4.1 and $10.6 \%$, respectively, $P=0.003$ ). This indicates that the abnormality of aneuploidy and large fragment chromosome causes genetic changes and disturbs the balance 
TABLE 5 | The rates of Pathogenic CNVs in isolated CNS abnormalities and CNS abnormalities with other ultrasound abnormalities.

\begin{tabular}{|c|c|c|c|c|c|}
\hline Classification & Number of fetuses & Number of fetuses with abnormal CNVs & P CNVs & VUS CNVs & p-values \\
\hline CNS abnormalities with other ultrasound abnormalities & 217 & 15 & $10(4.6 \%)$ & $5(2.3 \%)$ & - \\
\hline Total & 535 & 41 & $18(3.4 \%)$ & $23(4.5 \%)$ & 0.187 \\
\hline
\end{tabular}

$p>0.05$ compared with isolated CNS anomalies and CNS abnormalities with other ultrasound abnormalities via $\chi^{2}$ test.

CNS, Central Nervous System; P, pathogenic; CNVs, copy number variations; VUS, uncertain clinical significance.

TABLE 6 | Phenotypic characteristics of 318 fetuses with isolated CNS abnormalities.

\begin{tabular}{|c|c|c|c|c|}
\hline $\begin{array}{l}\text { Isolated CNS abnormalities } \\
\text { classifcation }\end{array}$ & $\begin{array}{l}\text { Number of } \\
\text { fetuses }\end{array}$ & $\begin{array}{c}\text { Number of fetuses with chromosomal } \\
\text { abnormalities }\end{array}$ & $\begin{array}{l}\text { Number of fetuses with } P \\
\text { CNVs }(<10 \mathrm{Mb})\end{array}$ & $\begin{array}{c}\begin{array}{c}\text { Number of fetuses with total } \\
\text { anomaly }\end{array}\end{array}$ \\
\hline Mild ventricular enlargement & 142 & 2 & 2 & $4(2.8 \%)$ \\
\hline Hydrocephaly & 9 & 0 & 2 & 0 \\
\hline ACC & 13 & 1 & 0 & $1(7.7 \%)$ \\
\hline Cerebellar hypoplasia & 4 & 0 & 0 & 0 \\
\hline Dandy-Walker syndrome & 3 & 0 & 0 & 0 \\
\hline Microcephaly & 6 & 1 & 0 & $1(16.7 \%)$ \\
\hline Choroid plexus cyst & 89 & 5 & 1 & $6(6.7 \%)$ \\
\hline Arachnoid cyst & 9 & 0 & 0 & 0 \\
\hline Subependymal cyst & 5 & 1 & 0 & $1(20 \%)$ \\
\hline Total & 318 & 12 & 9 & $6.6 \%(21 / 318)$ \\
\hline
\end{tabular}

ACC, Agenesis of the corpus callosum; CNS, Central Nervous System; CNVs, copy number variations; $P$, pathogenic.

between genes, thus leading to the malformation of fetal multisystems (Hsiao et al., 2009). The rate of pathogenic CNVs in CNS anomalies with other ultrasound anomalies was higher than that in isolated CNS anomalies (2.5 and 4.6\%), but the difference was not statistically significant $(p>0.05)$. Therefore, SNP array is recommended for fetuses with CNS abnormalities, especially for those with multiple CNS abnormalities. However, for fetuses with isolated CNS abnormalities, SNP array should not be considered because of their low incidence of microdeletions/ microduplications.

The rates of chromosomal abnormalities and pathogenic CNVs in isolated CNS abnormalities was 6.6\%. The rates of chromosomal abnormalities and pathogenic CNVs in fetuses with spine malformation, encephalocele, subependymal cyst, and microcephaly were higher than those with other isolated CNS abnormalities. Previous studies (Sun et al., 2015) have also demonstrated that isolated CNS abnormalities could still be detected at a rate of $6.5-8.3 \%$ in case of pathogenic CNVs by CMA, which could not be detected by traditional karyotype analysis.

Of the 41 cases with abnormal CNVs, 18 cases had pathogenic CNVs. Of these 18 pathogenic CNVs, eight cases were known as microdeletion/microduplication syndrome. There are many known pathogenic genes that can cause CNS abnormalities (Huang et al., 2012; Krutzke et al., 2016; Schumann et al., 2016). Eight cases with microdeletions were found in this study, including five cases with $16 \mathrm{p} 11.2$ microdeletion syndrome, two cases with 22q11.2 microdeletion syndrome, and one case with Miller Dieker syndrome (17p13.3p13.2 microdeletion). The most common is $16 \mathrm{p} 11.2$ microdeletion syndrome, with an incidence rate of $0.3 \%$ (Rosenfeld et al., 2010). The main clinical symptoms include intellectual disability and autism spectrum disorder (2015). The gene, T-box transcription factor 6 , is a key gene causing vertebral deformity in patients with $16 \mathrm{p} 11.2$ microdeletion syndrome (Al-Kateb et al., 2014). At present, there are few reports on fetuses with 16p11.2 microdeletion syndrome. Only a few studies (Hernando, 2002; Li et al., 2017) have reported the ultrasound anomalies related to $16 \mathrm{p} 11.2$ microdeletion syndrome include cardiac malformation, polycystic kidney, absence of nasal bone, single umbilical artery, intrauterine growth retardation, etc. In this study, the five cases with 16 p11.2 microdeletion syndrome had different ultrasound anomalies, including two cases with spine malformation, one case with hydrocephaly, one case with mild ventricular enlargement, and one case with other ultrasound abnormalities besides mild ventricular enlargement. SNP array showed that two cases had 22q11.2 microdeletion syndrome. The incidence of $22 \mathrm{q} 11.2$ microdeletion syndrome is about $1 / 4,000$, and its clinical phenotypes are diverse (Sullivan, 2008). About $80 \%$ of cases with 22q11.2 microdeletion syndrome have various types of cardiac malformations (Ferencz et al., 1989). In this study, the two fetuses with 22q11.2 microdeletion syndrome showed no cardiac malformation. Among these two fetuses with 22q11.2 microdeletion syndrome, one showed only choroid plexus cyst, while the other one had choroid plexus cyst and varus and polyhydramnios. In this study, the SNP array of a fetus showed there was a $5.2 \mathrm{Mb}$ deletion in p13.3p13.2 on 
chromosome 17, which could lead to the Miller-Dieker syndrome. The incidence of Miller-Dieker syndrome is about 1.2:100,000 (Kiiski et al., 2012; Roos et al., 2009), and is usually characterized by agenesis of the corpus callosum, microcephaly, etc (Tang et al., 2016). Ultrasound of this case in this study showed mild ventricular enlargement, cerebellar hypoplasia, and other ultrasound anomalies such as varus.

CMA also has its shortcomings, and cases with VUS CNVs make genetic counseling difficult. According to the literature (Breman et al., 2012; Faas et al., 2010; Hillman et al., 2011), the detection rate of VUS CNVs by CMA is 1.1-6\%. In this study, among the 535 cases with abnormal CNS, 23 cases had VUS CNVs, and the detection rate of VUS CNVs was $4.3 \%$, which was consistent with the previous reports. Among the 23 cases with VUS CNVs, eight cases were susceptibility loci for neurodevelopment, including three cases of $15 q 13.3$ duplications, one case of $16 \mathrm{p} 13.11$ duplication, one case of 1q21.1q21.2 duplication, one case of 1q21.1 deletion, one case of 3 p26.3 deletion, and one case of $15 q 11.2$ deletion. The susceptibility loci for neurodevelopment had incomplete penetrance, and may be associated with cardiovascular disease, cognitive impairment, behavioral disorder, and intellectual disability (Idit Maya et al., 2018). The incomplete penetrance of the susceptibility loci for neurodevelopment poses a challenge for genetic counseling (Oneda and Rauch, 2017). Some VUS cases including 3p22.1 deletion, 3p25.2 duplication, 3p26.3 deletion, $14 \mathrm{q} 21.2 \mathrm{q} 21.3$ deletion, $10 \mathrm{q} 24.31 \mathrm{q} 24.32$ duplication, $5 \mathrm{q} 35.3$ duplication, 1q31.1 duplication, may only contain 1-3 OMIM genes, which is not related to the nervous system, but it was exceeds the reporting threshold. In case 12, 18q21.33 deletion contain the exon 16-31 of PIGN, homozygous mutations in this gene lead to multiple congenital abnormalities-hypokalemiaepilepsy syndrome, the clinical phenotype is lack of motor development, seizures, multiple malformations and various congenital abnormalities involving the heart, urinary and gastrointestinal systems. The fetal was a carriers of recessive genetic diseases caused by PIGN genes with no further testing. In recent years, as a new technology, next-generation sequencing has been used to detect single gene mutations and CNVs, and may provide a more comprehensive method to better assess the prognosis of the fetus.

Combining karyotype analysis with SNP array can help parents with fetuses having CNS anomalies to make decisions on whether to terminate pregnancy. For example, in fetuses with mild ventriculomegaly, normal results from SNP array indicate that the fetus may have a better prognosis, and parents can choose to continue pregnancy. In this study, among the 523 fetuses with CNS abnormalities that were successfully followed up, the

\section{REFERENCES}

Hanson, E., Bernier, R., Porche, K., Jackson, F. I., Goin-Kochel, R. P., Snyder, L. G., et al. (2015). The Cognitive and Behavioral Phenotype of the 16p11.2 Deletion in a Clinically Ascertained Population. Biol Psychiatry. 77, 785-793. doi:10.1016/j.biopsych.2014.04.021 Committee Opinion (2016). Committee Opinion No. 682 Summary: Microarrays and Next-Generation Sequencing Technology: The Use of Advanced Genetic pregnancies were terminated for 25 fetuses in which karyotype analysis and SNP array showed normal results. Thirteen of these cases had severe nervous system malformations and 12 cases had severe multiple malformations, which accounted for the termination of pregnancies. Therefore, even if the SNP array results were normal, most of the parents with fetal CNS abnormalities and multiple malformations still decided to terminate pregnancy, because of refractoriness to the postnatal treatment and seriousness in the postnatal phenotype such as severe deformity, intellectual disability, etc (Volpe and Joseph, 2010).

Comparing with the traditional karyotype analysis, SNP array can find more abnormal CNVs in fetuses with CNS abnormalities. It is suggested that SNP array should be used in the prenatal diagnosis of fetuses with CNS abnormalities, which can enable better prenatal assessment and genetic counseling, and also affect obstetrical outcomes.

\section{DATA AVAILABILITY STATEMENT}

The original contributions presented in the study are included in the article/Supplementary Material, further inquiries can be directed to the corresponding authors.

\section{ETHICS STATEMENT}

The studies involving human participants were reviewed and approved by the local ethics committee at the Fujian Provincial Maternal and Child Health Hospital. The patients/participants provided their written informed consent to participate in this study.

\section{AUTHOR CONTRIBUTIONS}

Designed the study: MC and NL. Conducted the experiments: MC and HH. Performed the data analysis: LX. Wrote the manuscript: MC.

\section{FUNDING}

This work was funded by the Fujian Provincial Natural Science Foundation (no. 2017J01238), and the training project of young and middle-aged talents in health system of Fujian Province (grants 2020GGA020).

Diagnostic Tools in Obstetrics and Gynecology. Obstet Gynecol. 128, 1462, 1463. doi:10.1097/AOG.0000000000001814

Al-Kateb, H., Khanna, G., Filges, I., Hauser, N., Grange, D. K., Shen, J., et al. (2014). Scoliosis and Vertebral Anomalies: Additional Abnormal Phenotypes Associated with Chromosome 16p11.2 Rearrangement. Am. J. Med. Genet. 164, 1118-1126. doi:10.1002/ajmg.a.36401

Breman, A., Pursley, A. N., Hixson, P., Bi, W., Ward, P., Bacino, C. A., et al. (2012). Prenatal Chromosomal Microarray Analysis in a Diagnostic Laboratory; 
Experience with $>1000$ Cases and Review of the Literature. Prenat. Diagn. 32, 351-361. doi:10.1002/pd.3861

Cai, M., Lin, N., Su, L., Wu, X., Xie, X., Li, Y., et al. (2020). Copy Number Variations Associated with Fetal Congenital kidney Malformations. Mol. Cytogenet. 13, 11. doi:10.1186/s13039-020-00481-7

Cukier, H. N., Dueker, N. D., Slifer, S. H., Lee, J. M., Whitehead, P. L., Lalanne, E., et al. (2014). Exome Sequencing of Extended Families with Autism Reveals Genes Shared across Neurodevelopmental and Neuropsychiatric Disorders. Mol. Autism. 5, 1. doi:10.1186/2040-2392-5-1

Faas, B. H. W., van der Burgt, I., Kooper, A. J. A., Pfundt, R., Hehir-Kwa, J. Y., Smits, A. P. T., et al. (2010). Identification of Clinically Significant, Submicroscopic Chromosome Alterations and UPD in Fetuses with Ultrasound Anomalies Using Genome-Wide 250k SNP Array Analysis. J. Med. Genet. 47, 586-594. doi:10.1136/jmg.2009.075853

Ferencz, C., Neill, C. A., Boughman, J. A., Rubin, J. D., Brenner, J. I., and Perry, L. W. (1989). Congenital Cardiovascular Malformations Associated with Chromosome Abnormalities: an Epidemiologic Study. J. Pediatrics. 114, 79-86. doi:10.1016/s0022-3476(89)80605-5

Hadzagić-Catibusić, F., Maksić, H., Uzicanin, S., Heljić, S., Zubcević, S., Merhemić, Z., et al. (2008). Congenital Malformations of the Central Nervous system: Clinical Approach. Bosn. J. Basic. Med. 8, 356-360. doi:10.17305/bjbms.2008.2897

Hernando (2002). Comparative Genomic Hybridisation Shows a Partial De Novo Deletion 16p11.2 in a Neonate with Multiple Congenital Malformations. J. Med. Genet. 39, e24. doi:10.1136/jmg.39.5.e24

Hillman, S. C., Pretlove, S., Coomarasamy, A., McMullan, D. J., Davison, E. V., Maher, E. R., et al. (2011). Additional Information from Array Comparative Genomic Hybridization Technology Over Conventional Karyotyping in Prenatal Diagnosis: a Systematic Review and Meta-Analysis. Ultrasound. Obstet. Gynecol. 37, 6-14. doi:10.1002/uog.7754

Hsiao, C.-C., Tsao, L.-Y., Chen, H.-N., Chiu, H.-Y., and Chang, W.-C. (2009). Changing Clinical Presentations and Survival Pattern in Trisomy 18. Pediatrics. Neonatol. 50, 147-151. doi:10.1016/s1875-9572(09)60053-x

Huang, J., Wah, I. Y. M., Pooh, R. K., and Choy, K. W. (2012). Molecular Genetics in Fetal Neurology. Semin. Fetal. Neonatal. Med. 17, 341-346. doi:10.1016/j.siny.2012.07.007

Maya, I., Sharony, R., Yacobson, S., Kahana, S., Yeshaya, J., Tenne, T., et al. (2018). When Genotype is not Predictive of Phenotype: Implications for Genetic Counseling Based on 21,594 Chromosomal Microarray Analysis Examinations. Genet. Med. 20, 128-131. doi:10.1038/gim.2017.89

Kiiski, K., Roovere, T., Zordania, R., Von Koskull, H., and Horelli-Kuitunen, N. (2012). Prenatal Diagnosis of 17p13.1p13.3 Duplication. Case. Rep. Med. 2012, 840538. doi:10.1155/2012/840538

Krutzke, S. K., Engels, H., Hofmann, A., Schumann, M. M., Cremer, K., Zink, A. M., et al. (2016). Array-based Molecular Karyotyping in Fetal Brain Malformations: Identification of Novel Candidate Genes and Chromosomal Regions. Birth Defects Res A Clin Mol Teratol. 106, 16-26. doi:10.1002/bdra. 23458

Li, L., Huang, L., Lin, S., Luo, Y., and Fang, Q. (2017). Discordant Phenotypes in Monozygotic Twins with 16p11.2 Microdeletions Including the SH2B1 Gene. Am J Med Genet 173, 2284-2288. doi:10.1002/ajmg.a.38284
Oneda, B., and Rauch, A. (2017). Microarrays in Prenatal Diagnosis. Best. Prac. Res. Clini. Obstet. Gynaecol. 42, 53-63. doi:10.1016/j.bpobgyn.2017.01.003

Onkar, D, Onkar, P, and Mitra, K (2014). Evaluation of Fetal Central Nervous System Anomalies by Ultrasound and Its Anatomical Co-Relation. J Clin. Diagn. Res. 8, AC05-7. doi:10.7860/JCDR/2014/8052.4437

Reddy, U. M., Page, G. P., Saade, G. R., Silver, R. M., Thorsten, V. R., Parker, C. B., et al. (2012). Karyotype Versus Microarray Testing for Genetic Abnormalities after Stillbirth. N. Engl. J. Med. 367, 2185-2193. doi:10.1056/nejmoa1201569

Roos, L., Jonch, A. E., Kjaergaard, S., Taudorf, K., Simonsen, H., HamborgPetersen, B., et al. (2009). A New Microduplication Syndrome Encompassing the Region of the Miller-Dieker (17p13 deletion) Syndrome. J. Med. Genet. 46, 703-710. doi:10.1136/jmg.2008.065094

Rosenfeld, J. A., Coppinger, J., Bejjani, B. A., Girirajan, S., Eichler, E. E., Shaffer, L. G., et al. (2010). Speech Delays and Behavioral Problems are the Predominant Features in Individuals with Developmental Delays and 16p11.2 Microdeletions and Microduplications. J. Neurodevelop. Disord. 2, 26-38. doi:10.1007/s11689009-9037-4

Sahoo, T., Dzidic, N., Strecker, M. N., Commander, S., Travis, M. K., Doherty, C., et al. (2017). Comprehensive Genetic Analysis of Pregnancy Loss by Chromosomal Microarrays: Outcomes, Benefits, and Challenges. Genet. Med. 19, 83-89. doi:10.1038/gim.2016.69

Schumann, M., Hofmann, A., Krutzke, S.K., Hilger, A.C., Marsch, F., Stienen, D., et al. (2016). Array-Based Molecular Karyotyping in Fetuses with Isolated Brain Malformations Identifies Disease-Causing CNVs. J. Neurodev. Disord. 8, 11. doi:10.1186/s11689-016-9144-y

Sullivan, K. E. (2008). Chromosome 22q11.2 Deletion Syndrome: DiGeorge Syndrome/Velocardiofacial Syndrome. Immunol. Allergy. Clin. North. Am. 28, 353-366. doi:10.1016/j.iac.2008.01.003

Sun, L., Wu, Q., Jiang, S.-W., Yan, Y., Wang, X., Zhang, J., et al. (2015). Prenatal Diagnosis of Central Nervous System Anomalies by High-Resolution Chromosomal Microarray Analysis. BioMed. Res. Int. 2015, 1-9. doi:10. $1155 / 2015 / 426379$

Tang, XH, Yang, BC, Zhu, S, Su, J, Zhang, JM, Yin, YF, et al. (2016). Prenatal Diagnosis of Chromosome Abnormalities and Nine Nicrodeletion Syndromes using both Traditional Karyotyping and BoBs. Zhonghua fu chan ke za zhi 51, 325-30. doi:10.3760/cma.j.issn.0529-567X.2016.05.002

Volpeand Joseph, J (2010). Neurology of the Newborn. Major Probl Clin Pediatr. 1, 22. doi:10.1111/j.1469-8749.1959.tb08069.x

Conflict of Interest: The authors declare that the research was conducted in the absence of any commercial or financial relationships that could be construed as a potential conflict of interest.

Copyright () 2021 Cai, Huang, Xu and Lin. This is an open-access article distributed under the terms of the Creative Commons Attribution License (CC BY). The use, distribution or reproduction in other forums is permitted, provided the original author(s) and the copyright owner(s) are credited and that the original publication in this journal is cited, in accordance with accepted academic practice. No use, distribution or reproduction is permitted which does not comply with these terms. 